\title{
Developing Capacity for Research and Teaching in Higher Education: A Case of Makerere University
}

\author{
Christopher B. Mugimu, ${ }^{1, *}$, Mary Goretti Nakabugo ${ }^{2}$, \& Eli Katunguka-Rwakishaya ${ }^{3}$ \\ ${ }^{1}$ College of Education and External Studies, Makerere University, Uganda \\ ${ }^{2}$ School of Education, University of KwaZulu-Natal, Durban, South Africa \\ ${ }^{3}$ College of Veterinary Medicine, Animal Resources \& Bio-security, Makerere University, Uganda \\ *Corresponding author: College of Education and External Studies, Makerere University, P.O. Box 7062 Kampala, \\ Uganda. Tel: 256-704-900-255 E-mail: cbmugimu@gmail.com
}

Received: October 10, 2013

Accepted: December 2, 2013

Online Published: December 6, 2013

doi:10.5430/wje.v3n6p33

URL: http://dx.doi.org/10.5430/wje.v3n6p33

\begin{abstract}
Research and teaching are key pillars in higher education. This article examines the factors associated with the current faculty research and teaching agenda at Makerere University (MU) and explores the realities of ongoing capacity building for faculty in research and teaching. This research was guided by the following questions: What motivates faculty to engage in research and teaching? What contextual factors surround research and teaching capacity of faculty? What strategies are used to enhance the capacity of faculty in research and teaching? We utilized the Motivation System Theory (MST) as a lens to enable us better understand faculty' engagement in research and teaching. The study used mixed methods involving both quantitative and qualitative. The quantitative methods involved the use of a self-administered survey executed to the faculty. The qualitative methods involved in-depth interviews, gathering of faculty personal CVs and relevant documents from the MU website. To analyze and interpret qualitative data we used comparative approach to establish themes arising from the qualitative responses and portions of the questionnaire across the respondents. The key findings of this study revealed that the faculty of science-related disciplines were more productive (in terms of research, consulting work, completing PhDs) compared to their counterparts in the humanities. Furthermore, most of the faculty members perceived inadequate funding, heavy workloads, and poor motivation as being the major constraints to their research efforts and teaching. It was concluded that there was need to build a sustainable local capacity of faculty in terms of research and teaching.
\end{abstract}

Keywords: higher education; research; teaching; curriculum integration; Motivation System Theory (MST); instructional leadership; resources; capacity building

\section{Introduction}

Higher education institutions such as Makerere University (MU) are looked at as centers of excellence in terms of generating knowledge through rigorous research and teaching. Research and teaching are therefore important components of what goes on in higher education institutions (HEIs). However, evidence shows that different HEIs tend to give varying degrees of focus either on research or teaching. For instance, research-oriented universities usually put more emphasize on research activities than teaching. Subsequently, faculty members are given incentives to carry out research, sometimes at the expense of teaching. On the contrary, non-research-based universities may tend to put more emphasis on the teaching than research. As such, faculty members that are actively engaged in rigorous teaching may receive more incentives (i.e. recognition) for doing so than those involved in research. However, the question whether the most ideal situation would be to focus on both research and teaching remains highly contested. In this article, research refers to the creation of new knowledge or utilization of existing knowledge to bring about innovative applications directed towards specific practical aims and objectives (Creswell, 2005). Teaching refers to activities that enhance a supportive environment for promoting learning and acquisition of new knowledge. 


\subsection{Research and Teaching in Higher Education}

The question as to whether research and teaching are, can be, or should be linked is critical to all higher education systems, particularly in conceptualizing what constitutes a university (Deem \& Lucas, 2006, p. 1; Durning \& Jenkins, 2005). This question of the relationship between research and teaching in higher education remains contentious and highly debatable (Hattie \& Marsh, 1996; Robertson, 2007). The evidence that universities achieving high research output are also ranked high in terms of academic standards and teaching is also mixed at best. Notwithstanding whether research and teaching are related or not, they are both critical in higher education. It can no longer be disputed though that research and teaching are the key pillars of a university if the curriculum is tailored to achieving this goal (Elton, 2001). Therefore what is important is to ensure that research and teaching occur in HEIs to accomplish their mission as knowledge generation institutions. Therefore, the integration of research and teaching during curriculum design and implementation in higher education is extremely vital and should require much more attention than usually is the case in most HEIs. Angela Brew asserts that "if research and teaching are integrated in the curriculum to enhance students' involvement with the research activities of their faculty members, this should contribute greatly to their learning" (Brew, 1999, 2003). Levin also concurs with Brew that faculty members should tailor "their work as educators i.e. teaching, developing curriculum, counseling and advising students and community service" (Levin, 2006, p. 84) in order to facilitate experiential learning of students. Given that "research and learning both involve the pursuit of intellectually challenging ideas...if students are to benefit from their teacher's research, they should be more involved in helping to carry it out....careful attention should be given in curriculum design [to determine] how faculty research can benefit student learning” (Brew, 2003, p. 15).

As such, curriculum design should emphasize the integration of research and teaching to the extent that they become complementary in enhancing students' learning experiences (Bazeley, 1999; Coate, Barnett, \& William, 2001). Lewis Elton (2001, p. 54) also postulates that "the real locus of the teaching-research link does not [necessarily] lie in teachers or even in learners, but in the curriculum process - to be interpreted in the widest sense i.e. all that contributes to the learning experiences of students-in which both are engaged." Subsequently, what goes on in the training program and how learning is negotiated between faculty and students may impact on their experiences and future competences in significant ways. Hutchinson and Lovell (2004) also assert that the quality of graduate research training received by faculty may influence their research output and teaching in their future career as a whole because this will at least partially be determined by whether an individual has been properly socialized and grounded in an academic sense, or adequately motivated and skilled to do research using a variety of research methods that were acquired during the graduate research training. As such, the notion of a curriculum orientation that integrates research and teaching in higher education is fundamental in enhancing deep learning experiences and producing individuals that are highly skilled.

Furthermore, Robertson \& Bond (2001, p. 12) argue that "Those people who are keen on their research, conduct good research, and also make the best teachers. [Because] they are fresh, enthusiastic, and informed; they feed it into their students." In contrast, Hattie \& Marsh (1996) contend that because research and teaching are both time intensive, at times faculty members may fail to balance their time between actual teaching and research. Thus, over involvement in either of the two would compromise their research activity or teaching assignment. However, what motivates some faculty members to choose to engage more in either research or teaching or both is not clear. Some aspect of intrinsic and extrinsic motivations of faculty may come into play (Tien and Blackburn, 1996). Therefore, the notion of faculty motivation in terms of research and teaching is important (Jeans and Murphy, 2009).

\subsection{Theoretical Framework}

We utilized the Motivation System Theory (MST), as a lens, to help us better understand faculty's engagement in research and teaching. The MST assumes that actual achievement and competence of a person draws on one's being motivated, skillful, and biologically capable to attain a goal provided there is a responsive environment (Campbell, 2007; Ford, 1992). We find the MST to be ideal because of its relevance to the three research questions of this study. One of the questions probed for, what motivates faculty members to participate actively in research and teaching? Martin Ford (1992) suggest that "motivation [can be] defined in terms of three psychological functions that serve to direct, energize, and regulate goal-directed activity: personal goals, emotional arousal processes, and personal agency beliefs" (p.3). Personal goals refer to the kinds of consequences an individual decides to engage in and the means the individual uses to accomplish these consequences (Colbeck \& Weaver, 2008). Ford (1992) provides a taxonomy of twenty four goals, organized in six categories: affective (entertainment, tranquility, happiness, bodily sensations, and physical well-being), cognitive (exploration, understanding, intellectual creativity, positive self-evaluations), subjective organization (unity, transcendence), self-assertive social relationship (individuality, self-determination, 
superiority, resource acquisition), integrative social relationship (belongingness, social responsibility, equity, resource provision), task (mastery, task creativity, management, material gain, safety). Colbeck and Weaver (2008) also contend that "some of these goals may be associated with the justification of why some faculty members engage in public scholarship than others. Faculty members who value integrative social relationship goals such as social responsibility, for example, might be more likely to engage in public scholarship than faculty holding strong self-assertive social relationship goals such as superiority and resource acquisition” (p. 11). Likewise, faculty members orientated to cognitive goals such as exploration and intellectual creativity are likely to engage in self-directed research and teaching than those having the affective goal orientation such as entertainment and tranquility.

However, Colbeck \& Weaver (2008) argue that "goals alone are not enough to shape motivation. Individuals must also believe they have the personal agency to attain their goals" (p.11). Personal agency entails two important beliefs associated with motivation namely: capability and context beliefs. Ford (1992) defines capability beliefs as being "the evaluations of whether one has the personal skills needed to function effectively" to achieve his/her goals. The concept of self-efficacy plays a significant role in influencing individual expectations. For instance, faculty members who may feel are well-grounded in a variety of research methods and skills might be more likely to engage in research compared to those that feel are inadequately prepared. Faculty members with a strong personal belief in their competences in research and teaching are more likely to be more productive than those that are not.

The MST offers an interpretive framework that is in line with the second research question probed for, "What contextual factors surround research and teaching capacity of faculty?” The MST emphasizes contextual beliefs. Contextual beliefs "are the evaluations of whether one has the responsive environment needed to support effective functioning” (Ford, 1992, p. 124). Environment plays a significant role in shaping context beliefs. And a supportive environment for research and teaching in a university is important because it may strongly motivate faculty to become engaged in viable academic pursuits in numerous meaningful ways. According to Ford (1992, p. 131), a supportive environment must: (1) be congruent with an individual's personal agenda/goals, (2) be congruent with a person's biological, transactional, and cognitive capabilities, (3) have the materials and informational resources needed to facilitate goal attainment, and (4) provide an emotional climate that supports and facilitates effective functioning. The extent to which these MST principles are being met within the realities of research and teaching at MU is critical.

Colbeck \& Weaver (2008, p. 12) suggest that "goals, capability beliefs, and context beliefs set up a stage for a fourth component; emotional arousal". The subjective experience of an emotion reveals the degree of success, failure, or problems a person is experiencing - or anticipates, experiencing in pursuit of currently active personal goals. Strong emotions emerge in response to events that are important to the individual's goals, motives, or concerns. Emotions and goals are therefore closely linked. The notion of emotions is very relevant in our understanding of faculty engagement with research and teaching in higher education, given that faculty emotional arousal may be the source of energy to facilitate his/her effective functioning in circumstances that may require viable strategies for rapid and efficient mobilization and deployment of energy resources and transactional capabilities (Ford, 1992, p. 140). This is also consistent with the third research question: "What strategies are used to enhance the capacity of faculty in research and teaching?” Indeed, motivation is an important aspect of strategy setting in research and teaching. For instance, Ford argues that "motivation provides the foundation for learning, skill development, and behavior change by determining how, where, and to what ends people will invest" (p. 22) their strategies and energies in research or teaching.

\section{Conceptual Framework}

Therefore, MST provides an ideal framework to understand the factors motivating faculty engagement in research and teaching. The basic assumptions of the MST seem to be consistent with our conceptualization of faculty research and teaching. Our conceptualization draws mainly from Bland, Center, Finstad, Risbey, \& Staples (2006) and Dundar \& Lewis' (1998) studies on factors associated with enhancing faculty research productivity in higher education that revealed four key components namely: a) personal attributes, b) institutional structure c) effective instructional leadership, and d) departmental culture.

Personal attributes of the individual faculty include, but not limited to being properly socialized in research methods to gain the necessary competence, motivation and commitment to do research (Garde-Hansen \& Calvert, 2007; Mendoza, 2007). Faculty personal attributes may be so important in influencing their academic pursuits. Institutional structure refers to the size of institutional programs such as the number of faculty members in each of the units, the magnitude and distribution of teaching workload, number of students served, etc. Studies show that research productivity is also associated with institutional structure. Dundar \& Lewis (1998) assert that the larger the unit in terms of numbers of faculty members, the higher the research productivity other factors being equal. In other words, the more faculty 
members are likely to "share common research interests, [and] hence, may increase the likeliness of their cooperation and collaboration for joint research projects" ( p. 611). Larger departments could also be associated with greater access to important resources that are needed to support research. Important resources might include; computing facilities, a sizeable and current library, access to secretarial services and teaching assistants. Effective instructional leadership denotes an institution that has a well-established research orientation and teaching agenda, mission and vision that are clearly communicated to faculty. Departmental culture denotes a supportive environment for faculty efforts and needs, where active mentorship takes place, and an active culture of scholarship exists. An effective departmental culture and supportive environment would also provide essential financial and instructional resources, appropriately distribute teaching workloads, offer opportunities for professional development and sabbatical leaves, as well as to facilitate regular travel and research funds.

Dundar and Lewis (1998) concur that the culture of an institution is an important factor in determining the research performance of individual faculty and in establishing institutional research culture. However, the challenge facing HEIs is that research cultures do not happen spontaneously, but are created and nourished over time (Schein, 1992; Senge, Kleiner, Roberts, Ross, \& Smith, 1994). It may also be important to develop a research culture earlier on in ones academic career i.e. beginning with the undergraduate curriculum/programs. This makes sense since undergraduate students usually advance into graduate students and faculty (Garde-Hansen \& Calvert, 2007). It should be noted though that it takes serious commitment and effective instructional leadership to establish a lasting research culture in units of HEIs (Bland, et al., 2006). Instructional leadership should take on the mentorship role, rather than control, if they are to succeed in motivating faculty members to engage in worthwhile research and teaching agendas (Ford 1992). Thus, instructional leaders should also avoid the use of their authority to coerce faculty members to engage in research and teaching if they are to do so in meaningful ways.

Consistent with the MST, Staden, Boon, \& Dennill (2001) also found that faculty were motivated to do research and publish because of numerous contextual factors (which may be intrinsic and extrinsic) such as pay rise, recognition, appraisal, curiosity, and promotion. Tien (2000) also indicated that faculty motivation for promotion could be a good driving force to engage in active research. However, Court (1999) contends that motivation for just getting promoted could have counterproductive effects on the performance of faculty, especially when some of them apply for promotion without much success they may often become de-motivated which would typically have negative impact on their subsequent performance. This can be reflected in their reduced morale, negative attitudes of supervising students' projects, and reduced commitment to duty.

\subsection{Purpose of this Study}

This article examines factors surrounding faculty engagement in research and teaching and explores the ongoing capacity building of faculty in research and teaching.

\subsection{Questions}

This research was guided by the following research questions. What motivates faculty to engage in research and teaching? What contextual factors surround research and teaching? What strategies are used for faculty capacity building in research and teaching?

\subsection{Methods}

This study used mixed methods involving the use of self-administered survey questionnaires to a random sample of 123 academic staff from MU as shown in table 1. The faculty survey questionnaire comprised of six sections. Section A probed for demographic information such as age, sex, training undertaken, current academic position, academic advancement, current teaching load, sabbatical experiences, research and publications, conferences and workshops participation, graduate students supervision, and social academic network memberships. We also probed for how faculty felt about their research support and skills. Section C consisted of semi-structured questions and part F consisted of 14 questions that probed for qualitative information. 
Table 1: Sample of Participants

\begin{tabular}{ll}
\hline Full Professor & 7 \\
Associate Professor & 4 \\
Senior Lecturer & 27 \\
Lecturer & 37 \\
Assistant Lecturer & 31 \\
Teaching Assistant & 11 \\
Other (did not specify) & 6 \\
Total participants & 123 \\
\hline
\end{tabular}

All participants from the rank of Lecturer upwards held doctorates and were all actively involved in teaching and supervision of graduate students. Completed instruments were obtained from fifteen out of the twenty-two units at MU. Furthermore, we also carried out document analysis obtained from various sources including websites of different units across campus, library databases, graduation booklets, and 400 Curriculum Vitae for faculty. Descriptive statistics were generated from quantitative data using SPSS version 12. And to analyze and interpret qualitative data, we used a comparative approach to establish themes arising from the qualitative responses and portions of the questionnaire across the respondents. This article presents the findings from the analysis of the data gathered.

\subsection{Contextual Factors Surround Research and Teaching}

This section addresses research questions intended to help us understand the context in which research and teaching goes on at MU. Makerere University (MU) opened in 1922 and is the largest and oldest public university in Uganda. However, the persistent political conflict and instability in the 70s and 80s undermined its capacity in research and teaching especially following the massive attrition of highly qualified senior faculty who fled the country. The few competent senior faculty that remained also became unproductive and their research productivity stalled. The university fell into a state of rapid and persistent academic decline. Many international donor agencies also either reduced or discontinued their collaborative research financial support with Makerere (Musisi \& Muwanga, 2003). Given this dwindling international funding and lack of local government support, many educational programs suffered significant loss of stability and continuity. Subsequently, in the late 1980s, the Ugandan government adopted neo-liberal economic policies as a means to reform its higher education. This was in response to the International Monetary Fund (IMF) fiscal requirements and high external debt payments (Naiman \& Watkins, 1999; Obong, 2004). Consequently, the government of Uganda reduced its spending on social services, especially healthcare and education in order to be able to service the high external debt. This was followed by the introduction of cost-sharing policies in higher education that extended opportunities for a large number of students who could finance their education to access university admission through the Private Entry Scheme (PES). The PES expanded so rapidly that it led to bulging students' enrollments for both undergraduate and graduate programs in almost all units across campus. In twenty years following the inception of PES, the total students' population expanded from 5969 in academic year 1991/1992 to 38582 by 2010/2011, which is over 650 percent growth as reflected in figure 1 .

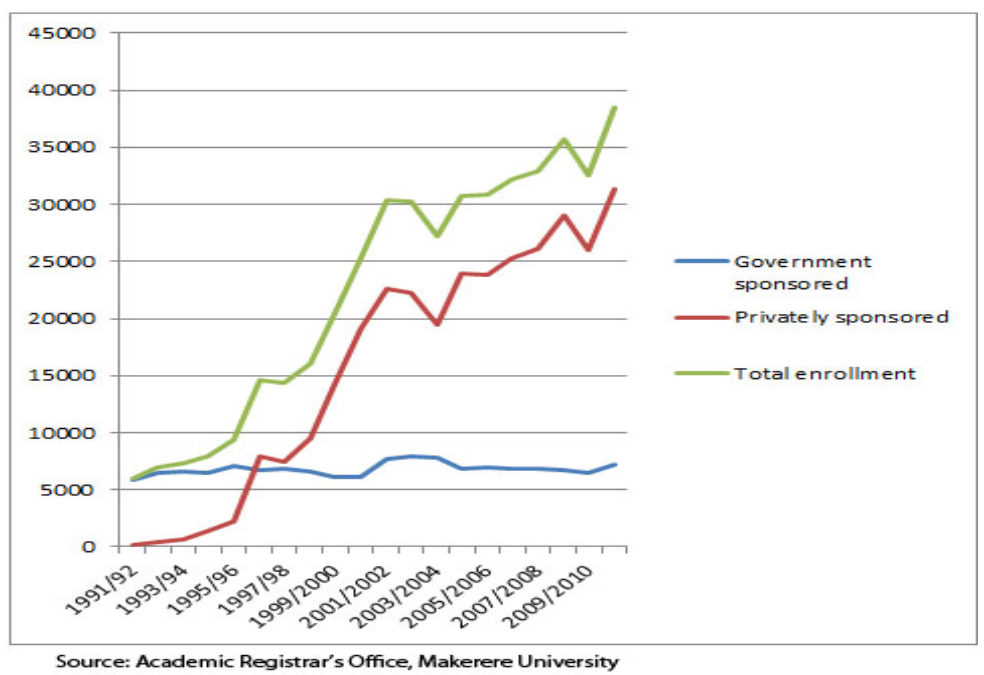

Figure 1: Students Enrollments 1991-2011 
The enrollment of privately-sponsored students on the PES virtually grew from 150 (3 percent) in 1991 to 31311 (81 percent) in 2011. This unprecedented rapid expansion of students' enrollments, being incommensurate to the available resources, has presented major challenges in stretching the over-burdened budgets, outdated infrastructure (i.e. poorly furnished lecture theatres, science laboratories, and halls of residences) as well as human resources (faculty, administrators, support staff). In the context of this article, perhaps the most challenging issue has become the extra teaching and administrative burdens created by the rapid increasing student enrollments on the remaining research-capable faculty.

University administrators and faculty have had to learn how to do more with less in order to keep the university going barely to maintain reasonable modest academic standards. However, critics contend that this unprecedented increase in students' enrollments could undermine the quality of university's educational programs and may lead to deteriorating academic standards under the current funding and enrollment realities (Musisi \& Muwanga, 2003).

Since 2000, significant efforts have been made to encourage and support faculty members to become productive in terms of research (ability to write winning research proposals, conference papers, and publishable work) and teaching excellence. These efforts emerged from both internal and external funding agencies such as Innovation at Makerere (I@MAK), the Swedish Development Agency (Sida/SAREC), the Norwegian Council of Higher Education's Program for Development Research and Education (NUFU), which have been directed to support faculty capacity building towards the improvement of their research culture and publication environment. These agencies have also sponsored undergraduate and graduate students to undertake research, internships, and fieldwork as reflected in Table 2 (Ogeda \& Nakabugo, 2006). This is in light of the fact that many of these undergraduate and graduate students could potentially become faculty members.

Table 2: Funding Agencies and Purpose of Funding for a period 2000 - 2010

\begin{tabular}{|c|c|c|c|}
\hline Period & $\begin{array}{l}\text { Funding } \\
\text { Agency }\end{array}$ & $\begin{array}{c}\text { Amount in } \\
\text { US\$s }\end{array}$ & Purpose \\
\hline $2000-2005$ & $\begin{array}{l}\text { Sida/SAREC } \\
\text { (Phase I) }\end{array}$ & $10,857,561$ & $\begin{array}{l}\text { - Improving the quality of lecturers and graduate } \\
\text { students through PhD training. } \\
\text { - Enhancing faculty supervision capacity. } \\
\text { - Conducting research and publishing results. } \\
\text { - Supporting ICT and digital library infrastructure } \\
\text { development. } \\
\text { - Enhancing research coordination and } \\
\text { administration. }\end{array}$ \\
\hline $2000-2006$ & NUFU (phase 3) & $4,424,554$ & $\begin{array}{l}\text { - Supporting faculty development, research and } \\
\text { publications. } \\
\text { - Financing travel expenses to attend conferences, } \\
\text { workshops, and seminars to disseminate research } \\
\text { findings. } \\
\text { - Supporting research in basic science, medicine, } \\
\text { child health, collaborative research in } \\
\text { environmental Toxicology and Zoonotic diseases, } \\
\text { etc. }\end{array}$ \\
\hline $2005-2009$ & $\begin{array}{l}\text { Sida/SAREC } \\
\text { (Phase II) }\end{array}$ & $20,568,181$ & $\begin{array}{l}\text { - Promoting research for the attainment of new } \\
\text { knowledge. } \\
\text { - Enhancing supportive environment for research and } \\
\text { research training. } \\
\text { - Improving graduate supervision experiences. } \\
\text { - Staff capacity development and research output. }\end{array}$ \\
\hline $2000-2010$ & I@Mak Project & $2,450,000$ & $\begin{array}{l}\text { - Promoting innovativeness among faculty in } \\
\text { partnering institutions through research and } \\
\text { publications. } \\
\text { - Enhancing faculty capacity building, improved } \\
\text { curriculum, research in decentralization, etc. }\end{array}$ \\
\hline
\end{tabular}


Given the increased revenue collections from privately-sponsored students and the improved capacity building initiatives for students and faculty (i.e. table 2) various stake holders anticipated better results from Makerere University in terms of research and teaching outputs. This research attempted to explore the status of research and teaching outputs in terms of publications, consultancies, completing masters and $\mathrm{PhD}$ students.

\section{Results}

\subsection{Faculty Research and Teaching Outputs}

Findings showed that some academic units from specific subject disciplines performed better on research productivity than others (see Table 3). For instance, Science-related units published more articles in refereed journals compared to humanities, and Agriculture was the highest. Out of the 713 articles published in peer-refereed journals, 569 (80 percent) were from science-related units contributed by either two or more authors and 139 (20 percent) articles by single authors. The plausible explanation for science-related academic units being more productive in terms of publishing in refereed journals as reflected in Table 3., could be due to the fact that virtually most of the publications contributed by science-related units were through predominantly joint collaborative efforts by either two or more authors.

Table 3: Shows Research Output by Faculty for the Period 2000-2006 Publications and other professional presentations

\begin{tabular}{|c|c|c|c|c|c|c|c|c|}
\hline & 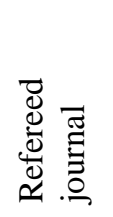 & 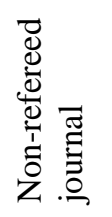 & 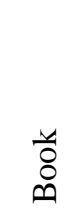 & 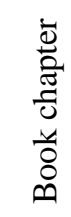 & 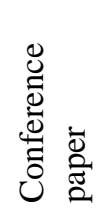 & 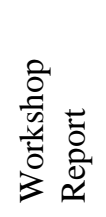 & 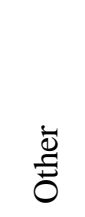 & 퓽 \\
\hline Education & 8 & 17 & 0 & 5 & 24 & 5 & 6 & 65 \\
\hline Arts & 3 & 0 & 9 & 4 & 14 & 1 & 0 & 31 \\
\hline Technology & 11 & 4 & 3 & 2 & 15 & 0 & 5 & 40 \\
\hline Veterinary & 111 & 19 & 5 & 14 & 15 & 8 & 5 & 177 \\
\hline Medicine & 94 & 4 & 0 & 1 & 31 & 22 & 7 & 159 \\
\hline Agriculture & 161 & 31 & 20 & 46 & 129 & 24 & 13 & 424 \\
\hline Science & 93 & 7 & 13 & 15 & 23 & 0 & 40 & 191 \\
\hline Social Science & 52 & 63 & 228 & 91 & 87 & 118 & 7 & 646 \\
\hline Comp Info Tech & 15 & 1 & 2 & 29 & 32 & 2 & 0 & 81 \\
\hline Public Health & 126 & 1 & 4 & 10 & 17 & 4 & 31 & 193 \\
\hline Economics & 6 & 1 & 5 & 3 & 20 & 3 & 3 & 41 \\
\hline Library science & 33 & 6 & 0 & 12 & 20 & 4 & 48 & 123 \\
\hline Total & 713 & 154 & 289 & 232 & 427 & 191 & 165 & 2171 \\
\hline
\end{tabular}

\subsection{Publications}

It is indeed a common practice in the science-related journals to find up to 10 authors contributing to one article. Conversely, their counterparts in the humanities and Social Sciences generally published as single authors i.e. out of the 646 publications from Social Sciences, 590 (91 percent) were contributed by single authors. The second plausible explanation could be because science faculty members tend to produce short journal articles based on their short-term studies. Natural scientists by the nature of their research, which is normally short-term and experimental rarely, develop monographs. Their counterparts in Social Sciences, on the other hand, contributed more books (79 percent), and book chapters (39 percent) than any of the other units put together. Researchers in the humanities usually undertake in-depth research studies spanning over a couple of years and have great appreciation of the importance of in-depth monographs in scholarship (Nakabugo \& Barrett, 2008). It is also reasonable to argue that producing monographs takes much longer to write and complete compared to a journal article.

It can also be noted in table 3 that those units that were most productive in terms of publications also appear to have presented more conference/workshop papers than their counterparts. These tended to be science-based units, such as Agriculture, Social Sciences, Computer Information Technology (CIT). Of all workshops attended by faculty members, 
39 per cent were local, 15 per cent regional and 46 per cent were in international settings. International settings refer to overseas, regional refers to neighboring countries of the Sub-Saharan Africa, and local refers to workshops conducted within Uganda and these attracted mainly local participants. It was also observed that in Uganda there was lack of credible internationally recognized peer-reviewed journal publishing houses. This was highlighted as one of the stumbling blocks undermining research publication activity. It can be also observed from the findings that those units especially science-related, whose faculty members mainly attended more international based conferences and workshops, contributed more publications in peer-reviewed journals compared to their counterparts. This is understandable, given that researchers in the natural sciences tended to attract more substantial external funding most of which account for travel and conference budgets (Nakabugo \& Barrett, 2008).

This seems to suggest that through participation in conferences and workshops, faculty did not only gain opportunities to network with colleagues from other international universities but also received feedback from peers to refine their papers for publication. Through international conferences it also became much easier for faculty to access and interact with editors and publishers from reputable international journals (Mugimu, Nakabugo, \& Katunguka-Rwakishaya, 2007) with possibilities of learning from them what is required to contribute and submit acceptable journal articles. Furthermore, given that it takes much more effort to publish an article in a prestigious peer refereed journal, it may be easier to do so if several faculty members worked jointly on a publication (Mugimu, et al., 2007). To this effect, teamwork has the advantage of encouraging themselves during the long waiting review process as well as sharing resources and personal expertise, thus, exploiting greater synergies that usually arise from sharing multi-perspectives and multidisciplinary expertise of peers in research and teaching.

It was also observed that at MU many faculty members might have been carrying out research but they were not reporting their outcomes mainly because from the responses, it was clear that most faculty members engaged in self-individual sponsored research and were therefore not obligated to report their research results to the university authorities.

\subsection{Research Consultancy Work by Faculty}

This research revealed that at Makerere, 289 (92 percent) consultancy projects had been completed between the year 2000-2006 and 21 (8 percent) projects were ongoing. Agriculture contributed 40 percent of the completed and 71 percent of the ongoing projects. Social Science conducted 16 percent of the completed projects while education had 14 percent. It is very clear that faculty members in science-related units particularly agriculture, medicine, and science did more consulting work compared to their counterparts in the humanities (i.e. education, arts, and social sciences all put together). As indicated earlier, many researchers usually engaged in consultancies on an individual basis and much of this work is not reported to the concerned university authorities and therefore may go unnoticed.

According to MST, a supportive environment and incentives are necessary to enhance research and teaching efforts in higher education. This study revealed that funding of research and teaching at Makerere were mainly supported by international agencies such as, the World Health Organization (WHO), UNESCO, USAID, NORAD, Carnegie Corporation of New York, SIDA/SAREC that cover 40 percent, followed by SGS and University Research Committee 28 percent, local government with 10 percent, and 22 percent from other sources. Agriculture was the best funded unit mainly supported by USAID and Rockfeller Foundation (RF). As such, having better access to funding could have contributed to Agriculture's leading position in research output described in the previous section. Based on this evidence, it can also be argued that there seems to be a correlation between amount of consultancy and research output in terms of publications.

\subsection{Production of Masters and PhD Students}

Table 4: MU Graduate Students Completing per Year between 2000-2006

\begin{tabular}{lllllllll}
\hline & 2000 & 2001 & 2002 & 2003 & 2004 & 2005 & 2006 & Totals \\
\hline Masters & 335 & 327 & 105 & 631 & 471 & 703 & 677 & 3249 \\
PhD & 11 & 12 & 06 & 22 & 21 & 24 & 23 & 119 \\
Totals & 346 & 339 & 111 & 653 & 492 & 727 & 800 & 3368 \\
\hline
\end{tabular}

Although there are increasing numbers of students graduating with Masters Degrees, there seems to be a limited number of students enrolling and/or graduating with doctorates (PhDs). The capacity of many academic units at MU to produce $\mathrm{PhD}$ graduates appears to be very low, with some producing only one graduate over a 7-year period, and others none at all. This compares starkly with other African universities such as University of Cape Town (UCT), which 
produced $127 \mathrm{PhD}$ graduates in 2005, which is more than what Makerere was able to produce in a period of seven years (i.e. Table 4). If MU is to compete favorably in the global knowledge economy, there is need to invest much more in graduate programs, especially at $\mathrm{PhD}$ level. However, we can consider the growing trend of master graduates completing as a positive indicator for capacity development. However, in view of the current realities, MU seems to be doing well with the penurious resources available to faculty for training and preparing graduate students.

\subsection{Obstacles to Research Capacity Development}

The faculty members were probed about the obstacles hindering the university's efforts toward the research capacity building of faculty. In this vain, the faculty highlighted inadequate funding, heavy workload, and lack of conducive research environment and poor motivation as key obstacles to their research efforts. Lack of information because of poor access to electronic databases, e-journals, e-books, and lack of faculty mentorship were of serious concern. Especially many academic units lacked senior faculty at the ranks of associate professor and full professors as reflected in table 5. This is even worse in consideration of the existing gender disparity among faculty, where male faculty members dominate especially at senior rank levels. Table 5 also clearly shows that generally in all units there are fewer faculty members than the estimated required numbers across all the different ranks. It is thus not surprising that many of these academic units faced the problem of lack of mentorship and inability to access research funding. The majority of respondents - 81 (66\%) agreed that it was difficult to get funding for research and 73 (59\%) were not assigned colleagues to provide the necessary mentorship they needed. The majority of faculty perceived the research financial and collegial support they got from the university as unsatisfactory. These findings suggest a relatively unsupportive environment to motivate faculty members to engage in meaningful research and teaching agenda at MU. According to MST the faculty context beliefs as to whether their individual or collegial contexts do support their goals and objectives in terms of research and teaching was critical (Ford, 1992).

Indeed the findings on the question of research culture in the units were mixed and fifty percent of respondents felt that their units had a strong research culture.

It is not surprising that the majority of the respondents were dissatisfied with their current research accomplishments and perceived their work environment as being unconducive to their research and professional growth. Yet, "the [university] environment must provide an emotional climate that supports and facilitates effective functioning" (Ford, 1992, p.131). Nevertheless, majority of the faculty members interviewed (73 percent) possessed either a personal desktop or laptop computer. However, owning a personal computer is one thing, ability to use it for research and teaching purposes is another. Besides, majority of the faculty reported to have received advanced training mainly from overseas international reputable universities. This may suggest that majority of them have been exposed to quality advanced graduate training programs. Again as earlier indicated, this would enhance their self-efficacy and self-confidence to engage in research and teaching. Conversely it is also possible that some faculty members find it extremely difficult to apply the scientific methodologies acquired from overseas to the local research context on their return home. If the institutional leadership does not provide the needed support to encourage and nurture individual personal goals as well as associated emotional satisfaction (Ford, 1992) that may emerge from engaging in research and teaching, it is unlikely that staff research output potential can be optimized.

\subsection{Research Support and Competencies}

According to MST faculty "capability beliefs" as to "whether one has the personal capabilities needed to attain a goal" (Ford, 1992, p. 74) in this case, engaging in research and teaching, is very important. Therefore, faculty were asked about their perceptions of the research support availability as well as their research competencies. This research showed that eighty three percent of respondents felt that they had adequate competence in computer skills, and 55 percent could use statistical computer packages in analyzing quantitative data. Seventy-nine percent of the faculty believed that they had acquired adequate training in research methodology and 74 percent felt comfortable with quantitative research methods, while 66 percent could blend both quantitative and qualitative research methods. Furthermore, 77 percent of the faculty felt they had adequate research proposal writing skills. It is clear that faculty had reasonable confidence in the needed research skills to perform or do research. Thus, it is very unlikely that the relatively low research output of faculty may not be because they lacked the research skills and expertise. Their research agenda may have been hampered by contextual-specific issues such as heavy teaching workloads, the lack of funding, and the dearth of supportive infrastructure at departmental, college and university level. 


\section{Policy Implications}

Utilizing the MST as a lens to better understand the status of faculty research and teaching at MU, this section highlights various important policy issues that may enhance faculty research output and teaching for upcoming universities in developing countries.

\subsection{Sharing Versus Competing for Resources}

In accordance with MST principles of integrative social relationships, especially the concepts of equity and resource provisionary goals are very important within the context of research and teaching. Equity goals may require that all faculty get fair treatment in terms of sharing available resources and opportunities. Resource provisional goals also have to do with ensuring that all faculty can equally have equal access to resources and materials such as information, guidance, advice, funds, and emotional support (Ford, 1992). In light of this, the notion of resource sharing is the preferred mode rather than competing for resources among units. It may not be necessary to compare research output among units, as this could be counterproductive as it may sometimes create unnecessary tensions and pressures among faculty of different units. Consequently, this practice tends to escalate competition among academic staff of course at the expense of strengthening collaboration between them. Rhoades (2001, p. 625) asserted that "What is productive for a single unit may not be so for the institution as a whole. As such, research output is increasingly a function of collaboration among faculty across units. In this context, initiatives that focus on academic units being compared in terms of research output and teaching can be counterproductive. Thus, Rhoades encourages university administration to avoid implementing strategies that escalate competition among different units.

\subsection{Focus on Establishing Strong Instructional Leadership in Units}

"Motivation can be facilitated or constrained, but not imposed - no one can be forced to care about something, be optimistic or pessimistic about something...” (Ford, 1992, p. 76)

If instructional leaders are to motivate their faculty to engage in meaningful research and teaching agendas, we find Ford's assertion on motivation in the quote vital. Effective instructional leadership is fundamental in creating a conducive and motivating research environment (Bland, et al., 2006). "Student's [academic] growth outcomes are greatest in departments with strong research and teaching environments" (Rhoades, 2001, p. 624). It takes strong instructional leadership to create and nurture good teaching and learning conditions in institutions. It requires strong effective instructional leaders in academic units to create viable mechanisms to overcome constraints such as inadequate funding, huge workloads, unconducive research environments, etc., that hinder faculty from being productive researchers and teachers. Effective instructional leaders are needed to break the existing barriers among units in order to establish interdisciplinary synergies and networks with colleagues from other reputable universities to enhance research output. Faculty mentorship is also very important. For instance, some of the best practices used at the University of Cape Town (UCT) is emphasizing faculty mentorship by assigning young ones with experienced senior faculty to provide the necessary guidance and mentorship (Finkelstein, Allen, \& Rhoton, 2003). This offers a captivating, supportive and nurturing environment to young faculty.

\section{Conclusions}

This research has offered some light into the factors affecting faculty research output and teaching at MU. What came out clearly was that the majority of faculty showed significant self-efficacy regarding their research and teaching competences. Most of them were confident with the kind of training they had received during their advanced graduate work and strongly believed in their ability to do considerable research and teaching. However, conditions beyond faculty control both personal and contextual such as heavy teaching loads, inadequate funding, and poor remuneration undermined their potential to engage in active research agendas, hampered their research output as well as teaching.

This notwithstanding, the much effort directed towards enhancing research output and capacity building cannot be underscored. For instance, the increasing interventions to support research capacity building for faculty and students through funding agencies as well as the renewed focus on expanding graduate programs and increasing graduate students' enrollments particularly at master and $\mathrm{PhD}$ levels has been noted. However, the number of students graduating with $\mathrm{PhDs}$ in all disciplines is still very low. We have also seen a renewed effort to faculty capacity building through improved curriculum renewal and development, and decentralization of power across units. Among other things, the efforts to improve information technology (IT) and library facilities as well as the move towards increasing the numbers of faculty members with PhDs that trained locally and internationally is a move in the right direction.

However, what continues to be a challenge at $\mathrm{MU}$ is the fact that most of the research activities taking place are 
individually faculty-driven in terms of commitment, funding, and dissemination, therefore, much of it is not reported to the university authorities and goes on unnoticed. Therefore, what is being reported here in this article might show a partial picture of what is actually taking place as far as faculty research output and teaching is concerned at MU. Nevertheless, a lot of important insights have been gained from this research. For example, looking at publications, consultancy work and $\mathrm{PhD}$ outputs there are significant disparities especially between science-related and humanities-related units. Science-related units were more productive or better performers in terms of publications, consultancy work and $\mathrm{PhD}$ outputs and this might explain why science-related units have attracted more funding from international agencies compared to their counterparts the humanities. In light of the MST's equity and resource provisionary goals principles, this may not be acceptable given that all units should have equal access to resources if the university is to be able to expedite the process of building capacity of its entire faculty.

It is also important to note that even though the findings of this study revealed that majority of the respondents felt confident with their research skills and believed that they could do research, the question that remains is: why so many of them still find it so difficult to engage in productive research activities? Why some other faculty members are able to engage in reasonable research activities yet they are all ideally working in similar contexts/environments?

In light of these and many other likely questions to arise, This kind of approach is of course consistent with the MST in that all faculty being exposed to other institutions with diverse research cultures and contexts are offered with great motivation opportunities to evaluate their own practices and be challenged to become more innovative. Indeed, According to Hossler et al. this is a very vital step in making the research and theory that undergirded their work accessible and useful in numerous meaningful ways.

Finally, the motivation to build sustainable local capacity in research and teaching of faculty must be a local initiative in order to cultivate and nurture desirable research cultures in spite of the current resource constraints. The rationale here is that once faculty members become adequately motivated to do research and teaching, they will be energized enough to set up their own personal goals for research and to creatively come up with innovative ways of overcoming the current obstacles hindering the active engagement in meaningful research efforts (Ford, 1992). The ultimate goal of the local universities such as MU will increasingly be to build professional research capacities of their faculty if they are to remain competitive in the global knowledge economy.

As earlier indicated, some of these provisions may include, but not limited to, the following: First, the need to strengthen the research culture of the university by establishing and strengthening mechanisms that enhance faculty research capacity. Second, the need also exists for the university leadership to create and nurture a supportive environment to encourage the growth of faculty research output and teaching. Third, the need to provide equitable research funding opportunities to allow all research capable faculty access these resources and information much easier by reducing the existing bureaucracies and ensuring effective instructional leadership at unit level. Of course these efforts will require careful planning, commitment, and dedication on the part of the university policy makers. Hossler et al. (2001b, p. 233) contend that "creating a common vision and speaking a common language speeds up the collaborative process and makes it easier to recruit and teach others about the task at hand." As a way forward, we also contend with Hossler et al.'s assertion that "the availability of external resources as instruments of change [is] important,....but may not be enough to enhance lasting change of important aspects of how college functions.... Furthermore, "...a focused program of institutional research and evaluation, and a will to act, all driven by a commitment to making a positive difference in the lives of individual students and the institution" (p. 234) is needed if universities in developing countries are to meet the demands of the global knowledge economy.

\section{References}

Bazeley, P. (1999). Continuing research by $\mathrm{PhD}$ graduates. Higher Education Quarterly, 53(4), 333-352. http://dx.doi.org/10.1111/1468-2273.00135

Bland, C. J., Center, B. A., Finstad, D. A., Risbey, K. R., \& Staples, J. (2006). The impact of appointment type on the productivity and commitment of full-time faculty in research and doctoral institutions. The Journal of Higher Education, 77(1), 89-123. http://dx.doi.org/10.1353/jhe.2006.0002

Brew, A. (1999). Research and teaching: changing relationships in a changing context. Studies in Higher Education, 24(3), 291-301. http://dx.doi.org/10.1080/03075079912331379905

Brew, A. (2003). Teaching and research: new relationships and their implications for inquiry-based teaching and learning in higher education. Higher Education Research \& Development, 22(1), 3-18. http://dx.doi.org/10.1080/0729436032000056571 
Campbell, M. M. (2007). Motivational Systems Theory and the academic performance of college students. Journal of College Teaching \& Learning, 4(7), 11-24.

Coate, K., Barnett, R., \& William, G. (2001). Relationships between teaching and research in higher education in England. Higher Education Quarterly, 55(2), 158-174. http://dx.doi.org/10.1111/1468-2273.00180

Colbeck, C. L., \& Weaver, L. D. (2008). Faculty engagement in public scholarship: a motivation system theory perspective. Journal of higher Education Outreach and Engagement, 12(2), 7-31.

Court, S. (1999). Negotiation the research imperative: the views of UK academics on their career opportunities. Higher Education Quarterly, 53(1), 65-87. http://dx.doi.org/10.1111/1468-2273.00113

Deem, R., \& Lucas, L. (2006). Learning about research: exploring the learning and teaching/research amongst educational practioners studying in higher education. Teaching in Higher Education, 11(1), 1-18. http://dx.doi.org/10.1080/13562510500400040

Dundar, H., \& Lewis, D. (1998). Determinants of research productivity in higher education. Research in Higher Education, 39(6), 607-631. http://dx.doi.org/10.1023/A:1018705823763

Durning, B., \& Jenkins, A. (2005). Teaching/research relations in departments: the perspectives of built environment academics. Studies in Higher Education, 30(4), 407-426. http://dx.doi.org/10.1080/03075070500160046

Elton, L. (2001). Research and teaching: conditions for a positive link [1]. Teaching in Higher Education, 6(1), 43-56. http://dx.doi.org/10.1080/13562510020029590

Finkelstein, L. M., Allen, T. D., \& Rhoton, L. A. (2003). An examination of the role of age in mentoring relationships. Groupd \& Organizational management, 28(2), 249-281. http://dx.doi.org/10.1177/1059601103028002004

Ford, M. E. (1992). Motivating humans Goals, emotions, and personal agency beliefs (First ed.). Newburry, California: SAGE Publications, Inc.

Garde-Hansen, J., \& Calvert, B. (2007). Developing a research culture in the undergraduate curriculum. Active Learning in Higher Education, 8(2), 105-116. http://dx.doi.org/10.1177/1469787407077984

Hattie, J., \& Marsh, H. W. (1996). The relationship betwen research and teaching: a Meta-Analysis. Review of Educational Research, 66(4), 507-542. http://dx.doi.org/10.3102/00346543066004507

Hossler, D., Kuh, G. D., \& Olsen, D. (2001a). Finding (more) fruit on the vines: using higher education research and institutional research to guide institutional policies and strategies (part II). Reasearch in Higher Education, 42(2), 223-235. http://dx.doi.org/10.1023/A:1026529721018

Hossler, D., Kuh, G. D., \& Olsen, D. (2001b). Finding fruit on the vines: using higher education research and institutional research to guide institutional policies and strategies. Research in Higher Education, 42(2), 211-221. http://dx.doi.org/10.1023/A:1026577604180

Hutchinson, S. R., \& Lovell, C. D. (2004). A review of methodological characteristics of research published in key journals in higher education: Implications for graduate research training. Research in Higher Education, 45(4), 383-403. http://dx.doi.org/10.1023/B:RIHE.0000027392.94172.d2

Jeans, R., \& Murphy, L. (2009). Investigating academic's motivation to pursue research activity. Newport CELT Journal, 2, 17-28.

Levin, J. S. (2006). Faculty work: tensions between educational and economic values. The Journal of Higher Education, 77(1), 62-88. http://dx.doi.org/10.1353/jhe.2006.0004

Mendoza, P. (2007). Academic capitalism and doctoral student socialization: A case study. The Journal of Higher Education, 78(1), 71-96. http://dx.doi.org/10.1353/jhe.2007.0004

Mugimu, C. B., Nakabugo, M. G., \& Katunguka-Rwakishaya, E. (2007). Exploring the factors affecting staff research output and completion rates of graduate students in Makerere University. Kampala: Makerere University.

Musisi, N. K., \& Muwanga, N. K. (2003). Makerere University in transition 1993-2000 Opportunities and challenges. Kampala: Fountains Publishers in with Partnership in Higher Education in Africa.

Naiman, R., \& Watkins, N. (1999). A survey of the impacts of IMF structural adjustment in Africa: growth, social spending, and debt relief. http://www.cepr.net/index.php/a-survey-of-the-impacts-of-imf-structural-...

Nakabugo, M. G., \& Barrett, E. (2008). Research Capacity Development in Irish and African Institutions: an interim 
report of findings from a stakeholder consultation in Irish and 4 African universities. Dublin: Irish-African Partnership for research Capacity Building.

Obong, Q. O. (2004). Academic dilemmas under neo-liberal education reforms: a review of Makerere University, Uganda. In P. Tiyambe \& A. Olukoshi (Eds.), African Universities in the twenty-first century (Vol. Volume 1 Liberation and internationalisation, pp. 108-125). Dakar, Senegal: CODESRIA.

Ogeda, M. C., \& Nakabugo, M. G. (2006). Decentralized service delivery: A Makerere University training pilot, documentation of implementation progress--status report as of 30th June 2005. Kampala: Makerere University.

Rhoades, G. (2001). Research and practice, managing productivity in an academic institution: Rethinking the whom, which, what, and whose of productivity. Research in Higher Education, 42(5), 619-632. http://dx.doi.org/10.1023/A:1011006511651

Robertson, J. (2007). Beyond the 'research/teaching nexus': exploring the complexity of academic experience. Studies in Higher Education, 32(5), 541-556. http://dx.doi.org/10.1080/03075070701476043

Robertson, J., \& Bond, C. H. (2001). Experiences of the relationship between teaching and research: what do academics value? Higher Education Research \& Development, 20(1), 5-19. http://dx.doi.org/10.1080/07924360120043612

Schein, E. H. (1992). Organizational culture and leadership. San Francisco: Jossey-Bass Publishers.

Senge, P. M., Kleiner, A., Roberts, C., Ross, R. B., \& Smith, B. J. (1994). The fifth discipline fieldbook: Strategies and tools for building a learning organization. New York: Bantam Doubleday Dell Publishing Group, Inc.

Staden, F. V., Boon, C., \& Dennill, I. (2001). Research publications output: A survey of the Psychology Department at UNISA. South African Journal of Psychology, 31(3), 50-57. http://dx.doi.org/10.1177/008124630103100307

Tien, F. F. (2000). To what degree does the desire for promotion motivate faculty to perform research? Testing the Expectancy Theory. Research in Higher Education, 41(6), 723-752. http://dx.doi.org/10.1023/A:1007020721531

Tien, F. F., \& Blackburn, R. T. (1996). Faculty rank system, research motivation, and faculty research productivity: measure refinement and theory testing. The Journal of Higher Education, 67(1), 2-22. http://dx.doi.org/10.2307/2943901

Toutkoushian, R. K., Porter, S. R., Danielson, C., \& Hollis, P. R. (2003). Using publications counts to measure an institution's research productivity. Research in Higher Education, 44(2), 121-148. http://dx.doi.org/10.1023/A:1022070227966

Volk, C. S., Slaughter, S., \& Thomas, S. L. (2001). Models of institutional resource allocation: Mission, market, and gender. The Journal of Higher Education, 72(4), 387-413. http://dx.doi.org/10.2307/2672889 